\title{
O-GlcNAcylation and inflammation: a vast territory to explore
}

\author{
Léa Baudoin ${ }^{1,2}$ and Tarik Issad ${ }^{1,2}$ * \\ 1 UMR8104, CNRS, Institut Cochin, Université Paris Descartes, Paris, France \\ 2 U1016, INSERM, Paris, France
}

\section{Edited by:}

Tony Lefebvre, University Lille 1, France

Reviewed by:

Giovanni Solinas, University of Gothenburg, Sweden

James M. Murphy, Walter and Eliza Hall Institute of Medical Research,

Australia

\section{${ }^{*}$ Correspondence:}

Tarik Issad, Department of Endocrinology, Metabolism and Diabetes, Institute Cochin, 22 rue Méchain, Paris 75014, France e-mail: tarik.issad@inserm.fr

\begin{abstract}
O-GIcNAcylation is a reversible post-translational modification that regulates the activities of cytosolic and nuclear proteins according to glucose availability. This modification appears to participate in several hyperglycemia-associated complications. An important feature of metabolic diseases such as diabetes and obesity is the presence of a low-grade chronic inflammation that causes numerous complications. Hyperglycemia associated with the metabolic syndrome is known to promote inflammatory processes through different mechanisms including oxidative stress and abnormally elevated protein O-GIcNAcylation. However, the role of O-GIcNAcylation on inflammation remains contradictory. O-GIcNAcylation associated with hyperglycemia has been shown to increase nuclear factor $\kappa B\left(N F_{\kappa} B\right.$ ) transcriptional activity through different mechanisms. This could contribute in inflammationassociated diabetic complications. However, in other conditions such as acute vascular injury, O-linked $\mathrm{N}$-acetyl glucosamine (O-GlcNAc) also exerts anti-inflammatory effects via inhibition of the NFKB pathway, suggesting a complex regulation of inflammation by $O$ GlcNAc. Moreover, whereas macrophages and monocytes exposed to high glucose for a long-term period developed a pro-inflammatory phenotype, the impact of O-GlcNAcylation in these cells remains unclear. A future challenge will be to clearly establish the role of O-GIcNAcylation in pro- and anti-inflammatory functions in macrophages.
\end{abstract}

Keywords: $O$-GIcNAc glycosylation, diabetes, metabolic syndrome, inflammation, cytokines, macrophages, nitric oxide, $\mathrm{NF}_{\mathrm{K} B} \mathrm{~B}$

\section{INTRODUCTION}

In the last decades, changes in lifestyle, including excessive energy intake and consumption of food enriched in saturated fat, combined with the lack of physical activity, have led to a dramatic increased prevalence of pathologies such as diabetes, obesity, and atherosclerosis. These pathologies are part of the metabolic syndrome, which constitutes one of the major threats to global health.

It is now well established that these metabolic diseases are associated with a low-grade chronic inflammation (1) that causes complications such as nephropathy, neuropathy, retinopathy, and atherosclerosis, and contributes to morbidity and mortality associated with the metabolic syndrome. This low-grade inflammation is characterized by an abnormal cytokine production. Thus, it has been demonstrated that the adipose tissue of obese individuals produce higher levels of the pro-inflammatory cytokine tumornecrosis factor $\alpha(\mathrm{TNF} \alpha)$ and other pro-inflammatory factors such as interleukin (IL) 6 (1). The excessive amount of nutritional lipids might have a role not only in the pathogenesis of obesityassociated insulin resistance but also in the chronic inflammation associated with this condition. Indeed, free fatty acids can activate the lipopolysaccharide (LPS) receptor toll-like receptor (TLR) 4 and induce the production of pro-inflammatory cytokines by macrophages (2). Not only lipids but also high-glucose concentrations are involved in inflammatory processes $(3,4)$. High glycemic index diets appeared to play a key role in the establishment and persistence of inflammation (5-7). In contrast, a 4 weeks food restriction in obese patients was sufficient to significantly reduce oxidative stress (8).

It is well documented that hyperglycemia associated with the metabolic syndrome promotes abnormally elevated protein $\mathrm{O}$ GlcNAcylation, which participates in the glucotoxicity phenomenon (9). O-GlcNAcylation is a reversible post-translational modification consisting in the addition of $\mathrm{N}$-acetylglucosamine to serine or threonine on cytosolic and nuclear proteins (Figure 1). Only two enzymes, $O$-GlcNAc transferase (OGT) and $O$-GlcNAcase (OGA), control the level of O-linked $\mathrm{N}$-acetyl glucosamine (OGlcNAc) on proteins. OGT uses UDP-GlcNAc, produced through the hexosamine biosynthetic pathway (HBP) to O-GlcNAcylate proteins, whereas OGA removes $O$-GlcNAc from proteins. Thus, according to glucose availability and its flux through the HBP, O-GlcNAcylation modulates protein functions by regulating their sub-cellular localization, stability, interaction with protein partners, or activity. More than 1000 proteins have now been identified as target of this modification, including transcription factors (10$17)$ and signaling molecules $(9,18-22)$ involved in glucose and lipid metabolism, insulin resistance, and inflammation. In addition to glucose, the $O$-GlcNAc also includes amine and acetyl moieties, and therefore also integrates amino-acids (glutamine) and fatty acid (AcetylCoA) metabolisms, suggesting that the availability of other nutrients may also be sensed by this pathway. Thus, infusion of a lipid emulsion in rats induced a twofold increase in 


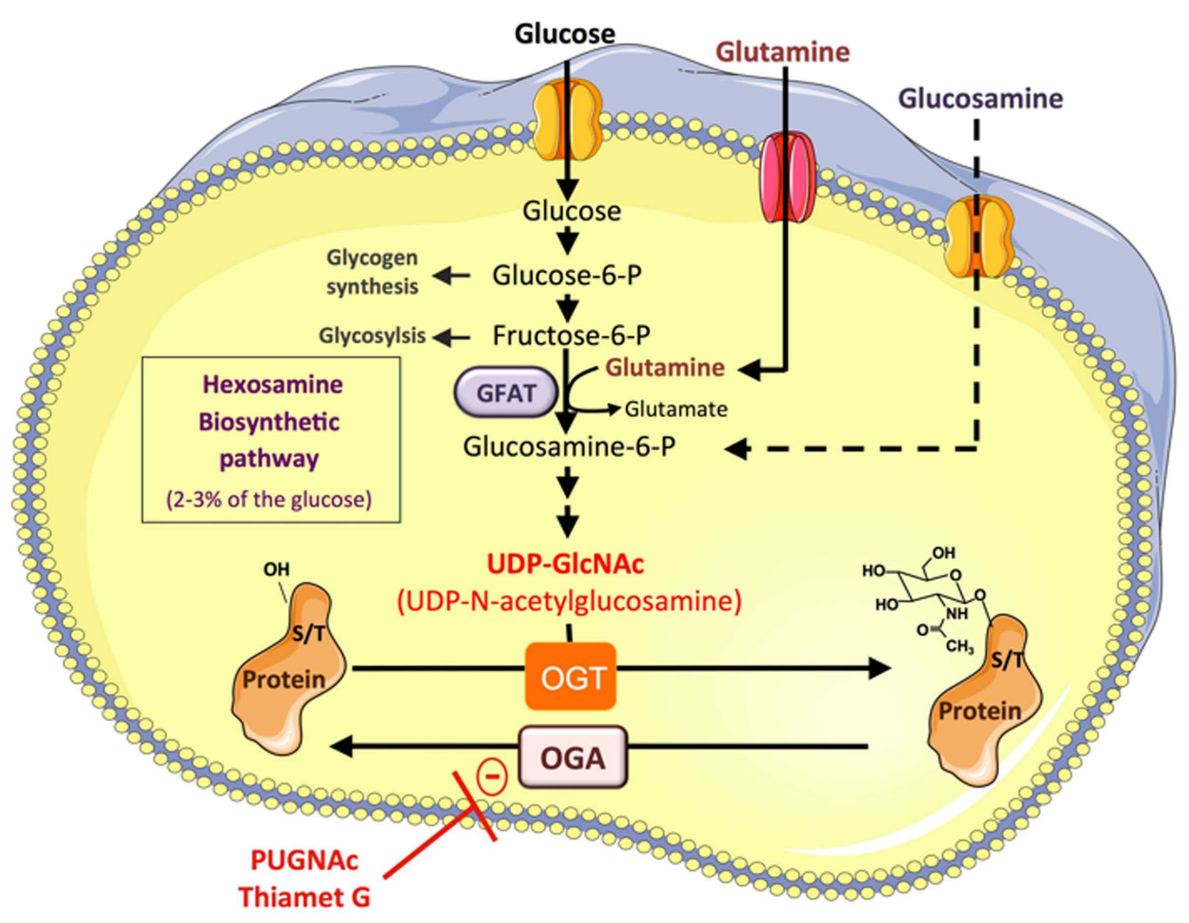

FIGURE 1 | Protein O-GIcNAcylation depends on the flux of glucose through the hexosamine biosynthesis pathway. A small fraction of the glucose entering the cell feeds the hexosamine biosynthetic pathway (HBP) to produce UDP-GIcNAc, the substrate used by

$O$-GlcNAc-transferase (OGT) to add $N$-acetyl glucosamine on serine or threonine residues of cytosolic or nuclear proteins. This dynamic and reversible post-translational modification controls the activity, the localization, or the stability of proteins according to glucose availability. Glucose enters the HBP as fructose-6-phosphate. The latter is converted to glucosamine-6-phosphate by the glutamine:fructose-6-phosphate amidotransferase (GFAT), the rate limiting enzyme of the pathway. After a subset of reactions, UDP-N-acetylglucosamine (UDP-GIcNAc) is generated and used by OGT to add GIcNAc on serine or threonine residues of target proteins. The O-GIcNAc moiety is removed from O-GlcNAc-modified proteins by the O-GIcNAcase (OGA). Experimentally, O-GlcNAcylation of proteins can be increased by incubating the cells with high concentrations of glucose, or with glucosamine, which bypass the rate limiting step catalyzed by GFAT. Inhibitors of OGA such as

O-[2-acetamido-2-deoxy-D-glucopyranosylidene] amino- $N$-phenylcarbamate (PUGNAc) or (3aR,5R,6S, 7R,7aR)-2-(ethylamino)-3a,6,7,7a-tetrahydro-5(hydroxymethyl)-5H-Pyrano[3,2-d]thiazole-6,7-diol (Thiamet-G) can also be used to increase the $O$-GlcNAc level on proteins.
UDP-GlcNAc content in skeletal muscle, associated with insulin resistance. Moreover, fatty acids can directly regulate the expression of glutamine:fructose-6-phosphate amidotransferase (GFAT) (23) and other enzymes of the HBP pathway (24) in muscle and pancreatic $\beta$-cell. Therefore, increased nutrients, and particularly increased blood glucose and fatty acids levels associated with excess food intake, obesity, and/or diabetes, are likely to impact numerous cellular processes, including those involved in inflammation, through protein O-GlcNAcylation.

\section{0-GIcNAcylation, DIABETIC COMPLICATIONS, AND INFLAMMATORY PROCESSES}

A number of experimental data have suggested the involvement of the HBP in pathological manifestations of the metabolic syndrome, such as diabetic associated-kidney disease. Indeed, one-third of diabetic patients will develop diabetic nephropathy, a chronic microvascular complication leading to a progressive decline in renal function, decreased glomerular filtration rate and proteinuria. Clinical trials have demonstrated that high glucose is central to the pathogenesis of diabetic nephropathy (25), and the beneficial effect of glycemia correction on renal complications has been demonstrated (26). Mesangial cells are smooth muscle-like pericytes that surround the filtration capillaries within glomerulus (27). In these cells, glucose flux, through the HBP pathway, regulates the expression of pro-fibrotic factors such as transforming growth factor $\beta 1$ (TGF $\beta 1$ ) and plasminogen activator inhibitor 1 (PAI-1), and extracellular matrix components (28, 29), at least in part via the O-GlcNAcylation of transcription factors such as Sp1 $(11,30)$. In mesangial cells, the HBP pathway also regulates the expression of pro-inflammatory factors such as vascular cell adhesion molecule-1 (VCAM-1), IL6, and TNF $\alpha$, through the nuclear factor $\kappa \mathrm{B}(\mathrm{NF} \kappa \mathrm{B})$ pathway (31). Abnormal activation of the NFKB pathway is certainly a major contributor in inflammation-associated diabetic complications. In vascular smooth muscle cells, high-glucose conditions resulted in NFKB activation (32). Peripheral blood mononuclear cells isolated from patients with diabetic nephropathy showed an increased activation of NFKB that could be corrected by anti-oxidant treatment (33, $34)$. Glucose oxidative stress is obviously central to glucotoxicity in diabetic conditions (35), and a link between hyperglycemia, oxidative stress, and O-GlcNAcylation has been proposed, reinforcing the potential involvement of O-GlcNAcylation in inflammation 
$(36,37)$. Therefore, exploring the potential regulation of NFKB activity by O-GlcNAcylation in different settings is of paramount importance.

\section{0-GIcNAcylation AND THE NFKB PATHWAY}

The transcription factor $\mathrm{NF \kappa B}$ is involved in a large number of cell functions including apoptosis, cell survival, and differentiation, and is critical to immune response and inflammation. NFKB family comprises five proteins, p65 (RelA), RelB, c-Rel,

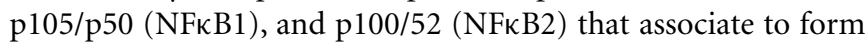
distinct homo and hetero-dimeric complexes (38-40). In nonstimulated cells, NFKB is inactive and is retained in the cytoplasm by the inhibitor of $\kappa \mathrm{B}$ (ІКB) (Figure 2). Upon stimulation by pro-inflammatory cytokines, LPS, or growth factors, IкB is phosphorylated by the I $\mathrm{B}$ kinase (IKK). This phosphorylation leads

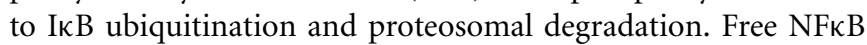
can then translocate into the nucleus to activate its target genes (38-40).

Nuclear factor $\kappa \mathrm{B}$ activation has been implicated in the metabolic syndrome and in diabetes pathogenesis (43-46). Because $\mathrm{NF} \kappa \mathrm{B}$ is mainly regulated by post-transcriptional modifications (with an important role of phosphorylation and acetylation), and because high glucose is known to activate $\mathrm{NF \kappa B}$ and stimulate its target genes, different studies focused on the potential role of $O-G l c N A c$ on NFKB activation.

\section{0-GIcNAcylation AS A POSITIVE REGULATOR OF NFKB ACTIVITY}

In the first study addressing this question, mesanglial cells treated with glucosamine or high-glucose exhibited an increased nuclear protein binding to NFKB consensus sequences in an electromobilty shift assay, correlated with O-GlcNAcylation of p65 (31). This observation suggested that NFKB O-GlcNAcylation could play a part in inflammatory processes. However, in that first study, the $O$ GlcNAc modification sites on NFKB had not been identified and the mechanism by which O-GlcNAc modification led to NFкB activation remained unclear (31).

It now clearly appears that different mechanisms, acting at various cellular levels, are involved in the effects of O-GlcNAcylation on activation of NFKB signaling. First, O-GlcNAcylation can regulate the interaction between $\mathrm{NF} \kappa \mathrm{B}$ and its inhibitor I $\kappa \mathrm{B}$. In porcine vascular smooth muscle cells, it has been demonstrated that downregulation of O-GlcNAcylation mediated by OGA over-expression inhibits hyperglycemia-induced NFKB activation. In contrast, an increase in O-GlcNAcylation mediated by OGT over-expression increases NFKB activity (41). These effects were due to an increase in O-GlcNAcylation of RelA on T352 that decreases its affinity for I $\mathrm{B}$, leading to an increased nuclear translocation of RelA [Figure 2A (I)]. This could contribute to the sustained activation of NFKB that is associated with diabetes (41). Another study indicated that O-GlcNAcylation increases $\mathrm{NF} \kappa \mathrm{B}$ transcriptional activity by promoting its acetylation (42). Indeed, chromatin immunoprecipitation assays demonstrated that, upon induction with TNF $\alpha$, OGT localizes to NFKB-regulated promoters. OGT siRNA experiments showed that OGT protein was required for NFKB-dependent transcription. The mechanism involved was the attachment of $\mathrm{O}$-GlcNAc moiety to T305 on RelA that promoted $\mathrm{NF} \kappa \mathrm{B}$ transcription by potentiating $\mathrm{p} 300$-dependent acetylation on K310 [Figure 2A (II)] (42).
The O-GlcNAcylation of NFאB also appears to play an important role in the immunity and the production of pro-inflammatory cytokines by T lymphocytes. Golks et al. first showed that OGT was necessary for activation of $\mathrm{T}$ lymphocytes by the T-cell receptor (TCR), inducing O-GlcNAcylation of p65 and stimulation of NFKB-dependent transcription (47). More recently, it was reported that in these cells, the c-Rel subunit of NFKB was modified by O-GlcNAcylation on Ser 350 [Figure 2A (III)]. This modification increased c-Rel transcriptional activity and was necessary for c-Rel mediated expression of IL2, IFNG, and CSF2 in response to TCR activation (48). Importantly c-Rel O-GlcNAcylation was not required for $\mathrm{TNF} \alpha$ - or TCR-induced expression of other $\mathrm{NF} \kappa \mathrm{B}$ target genes, such as NFKBIA (which encodes I $\mathrm{B} \alpha$ ) and TNFAIP3 (which encodes A20), indicating a gene specific requirement of c-Rel O-GlcNAcylation (48). These results suggest that during chronic hyperglycemia, an increase in c-Rel O-GlcNAcylation could contribute to type- 1 diabetes progression by enhancing the production of Th1 pro-inflammatory cytokines, leading to pancreatic $\beta$ cells destruction $(48,49)$. Finally, O-GlcNAcylation of IKK [Figure 2A (IV)] has also been demonstrated, resulting in an increase in its kinase activity, leading to subsequent increase in phosphorylation, and degradation of I $\mathrm{B}$ and stimulation of NFKB activity in cancer cells (50). Whether this mechanism is also operative in the context of hyperglycemia-induced inflammation remains to be evaluated.

\section{0-GIcNAcylation AS A NEGATIVE REGULATOR OF NFKB ACTIVITY}

Whereas O-GlcNAcylation is generally found associated with an increased in NFKB activity in diabetic conditions, in some situations, $\mathrm{O}$-GlcNAc appears, however, to reduce its pro-inflammatory activity (51-53). Thus, in a rat model of trauma-hemorrhage followed by fluid resuscitation, increased O-GlcNAcylation induced by glucosamine or PUGNAc significantly improved cardiac function and peripheral organ perfusion, and decreased the circulating levels of pro-inflammatory cytokines TNF $\alpha$ and IL6 $(51,52)$. These authors observed that increased O-GlcNAcylation reduces I $\mathrm{B}$ phosphorylation and $\mathrm{NF} \kappa \mathrm{B}$ signaling in cardiac tissue from trauma-hemorrhage treated rats. Moreover, O-GlcNAcylationinducing treatments appear to have anti-inflammatory and vasoprotective effects during acute vascular injury $(54,55)$. Indeed, Xing et al. showed that in rat aortic smooth muscle cells, OGlcNAcylation of p65 NFкB upon PUGNAc or glucosamine treatment was accompanied by a reduction in TNF $\alpha$-induced phosphorylation on serine 536, resulting in increased association of $\mathrm{NF} \kappa \mathrm{B}$ with $\mathrm{I} \kappa \mathrm{B}$, decreased NFKB activity and inhibition of the production of pro-inflammatory mediators (Figure 2B) (53).

It therefore appears that, depending on the cellular context and type of insult (chronic hyperglycemia versus acute vascular injury), O-GlcNAcylation may have different effects on the NFкB pathway, resulting in either pro- or anti-inflammatory outcomes.

\section{0-GIcNAcylation AND MACROPHAGE ACTIVITY}

Monocytes and macrophages play central roles in acute and chronic inflammatory processes. As mentioned previously, insulin resistance, obesity, and diabetes are associated with recruitment of pro-inflammatory monocytes/macrophages in different organs, including adipose tissue, liver, pancreas, as well as 

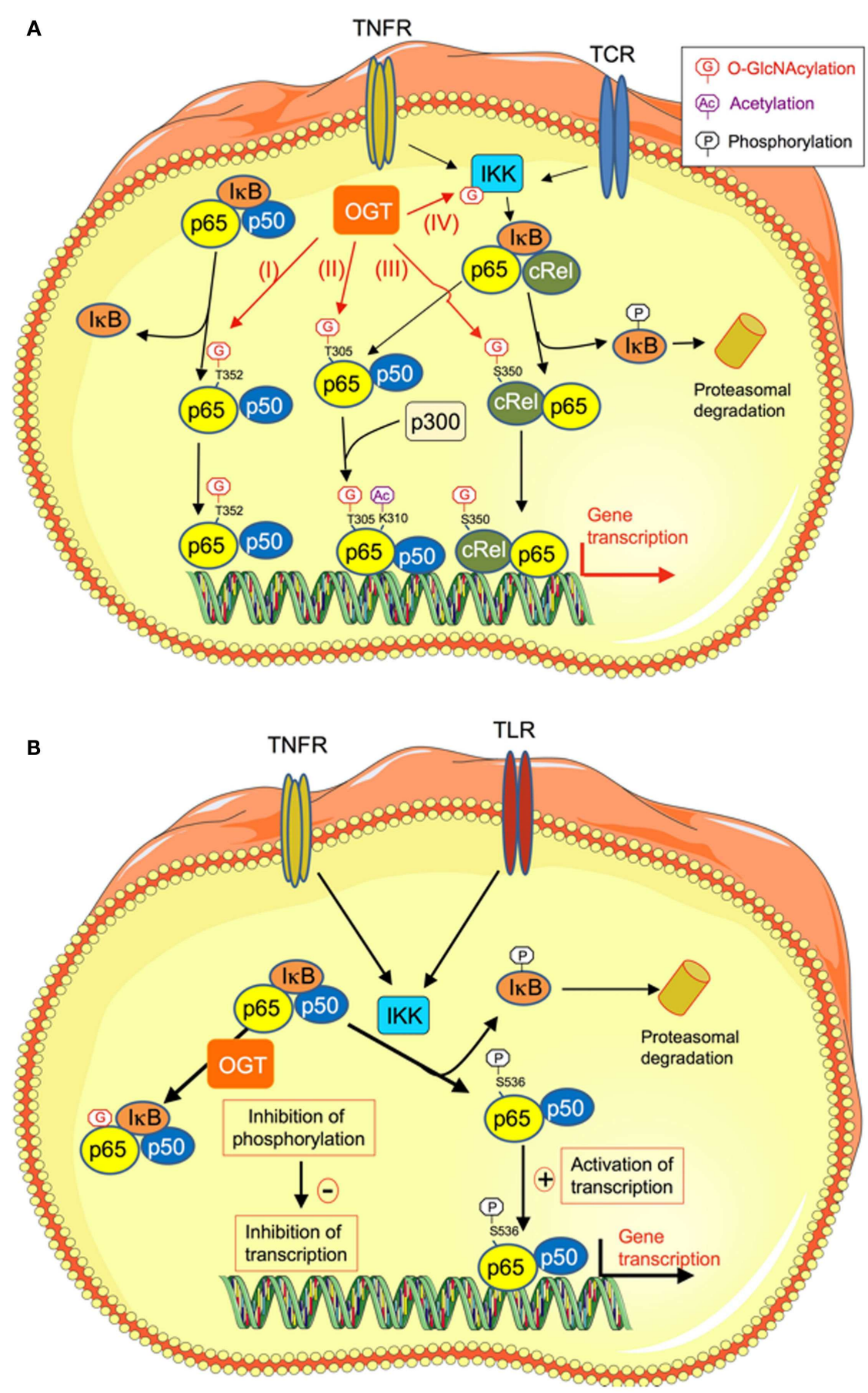

FIGURE 2 | O-GIcNAcylation regulates $\mathrm{NF}_{K} \mathrm{~B}$ transcriptional activity through different mechanisms. (A) O-GlcNAcylation stimulates NFKB transcriptional activity. High-glucose conditions are known to promote inflammatory processes through different mechanisms, including increased O-GIcNAcylation of NFKB. Several mechanisms have been described that could account for increased transcriptional activity of this factor upon O-GlcNAcylation. (I) O-GIcNAcylation of p65/RelA on T352 decreases its affinity for $1 \kappa B$, resulting in increased in its nuclear localization and transcription of its target genes (41). (II) O-GIcNAcylation of T305 on RelA promotes NFKB transcriptional activity by potentiating its p300-dependent acetylation on K310 (42). (III) O-GlcNAcylation of c-Rel on S350. This modification increases c-Rel DNA binding and transcriptional activity. (IV) O-GIcNAcylation of the $\beta$-subunit of IKK on Ser733 stimulates its activity, resulting in increased phosphorylation and degradation of $\mathrm{I}_{\kappa} \mathrm{B}$, and thereby increased $\mathrm{NF} \kappa \mathrm{B}$ activity.

(B) O-GlcNAcylation inhibits NFKB transcriptional activity.

O-GIcNAcylation-inducing treatments appear to have anti-inflammatory and vaso-protective effects during acute vascular injury. In rat aortic smooth muscle cells, O-GIcNAcylation of NFKB specifically inhibits its phosphorylation on Ser 536, while leaving other phosphorylation sites unaffected. This results in increased $\mathrm{NF}_{\mathrm{KB}}$ binding to $\mathrm{IkB}$, inhibition of TNF $\alpha$-induced NFKB DNA binding, and reduction of expression of genes coding for inflammatory mediators (TNFR, TNF $\alpha$ receptor; TCR, T-cell receptor; IKK, IK kinase). 
blood vessels wall (56-62). Numerous studies have shown that macrophages/monocytes submitted to long-term exposure to high-glucose concentrations developed a pro-inflammatory phenotype. Indeed, in human monocytic cells THP1, high glucose $(15 \mathrm{mmol} / \mathrm{L})$ for $72 \mathrm{~h}$ increased gene expression of the proinflammatory factors monocyte chemotactic protein 1 (MCP1), IL1 $\beta$, and TNF $\alpha$. Of interest, in this study, the NFкB activation played an important role in the high glucose-induced MCP1 transcription (63). In THP1 cells, exposure to high glucose also increased the RNA and protein levels of TLR2 and TLR4, which play key roles in innate immune response and inflammation. TLR2 and TLR4 activate MyD88 dependant signaling and induce NFKB transactivation, leading to the production of pro-inflammatory cytokines. These up-regulations of TLR2 and TLR4 under highglucose condition seemed at least in part mediated by protein kinase C (PKC) (64). In RAW 264.7, a murine macrophages cell line, high-glucose alone did not induce inflammatory mediator expression but increased inducible nitric oxide synthase (iNOS) expression and nitric oxide (NO) production in response to LPS. This effect appeared to be mediated by NFкB activation (65). High-glucose also increased IL1 $\beta$ secretion from LPS activated macrophages, a risk factor in diabetes that contributes to pancreatic $\beta$-cell damage (66). This effect appeared to involve activation of ERK1/2, JNK1/2, and PKC $\alpha$ and $\delta$ in macrophages cultured in high-glucose conditions (65).

In vivo hyperglycemia also affects the inflammatory profile of macrophages. An increased pro-inflammatory profile was observed in peritoneal macrophages from mice two weeks after diabetes induction with alloxan or streptozocin $(67,68)$. However, peritoneal macrophages from mice with 4 months streptozotocin-induced diabetes displayed complex modification of the pro-inflammatory profile, with increased NO production but decreased TNF $\alpha$ and IL6 in response to LPS stimulation (69). Another study showed impaired inflammatory response to multiple TLR ligands in alveolar macrophages from 2 weeks streptozotocin-induced diabetic mice (70). Therefore, in vivo hyperglycemia may have complex effects on macrophages functions, depending on their tissue of origin and on the duration of the diabetes.

High-glucose concentrations may affect macrophages functions through numerous mechanisms, including oxidative stress, activation of PKC, and/or MAP kinases, advanced glycation end products, as well as protein O-GlcNAcylation. Only a few studies evaluated the role of $\mathrm{O}-\mathrm{GlcNAcylation}$ in macrophages functions, and contradictory results were obtained.

In the human monocyte THP1 cell line, high-glucose concentrations and PUGNAc increased the expression and the secretion of macrophage inflammatory protein MIP1 $\alpha$ and $\beta$ through OGT dependent epigenetic mechanisms (71).

On the other hand, glucosamine exerted neuroprotective effects via suppression of post-ischemic microglia inflammation in rat brain after ischemia/reperfusion injury (72). Accordingly, in cultured mouse BV2 microglial cells and RAW264.7 macrophages, Hwang et al. observed that glucosamine suppressed LPS-induced up regulation of pro-inflammatory molecules by inhibiting NFкB activation by LPS. Glucosamine, which bypass the rate limiting step of the HBP, is often used to increase O-GlcNAcylation in cells. Unexpectedly, in this study, glucosamine induced a decrease in NFкB O-GlcNAcylation. This counter-intuitive result was explained by an inhibitory effect of glucosamine on an LPS-induced interaction between OGT and NFKB (72). More recently, the same group obtained similar results with cRel in BV2 microglial cells, showing glucosamine inhibition of LPSinduced cRel-OGT interaction, associated with decreased OGlcNAcylation of c-Rel and subsequent inhibition of its transcriptional activity (73). However, the mechanism by which glucosamine may interfere with the LPS pathway and affect OGT$\mathrm{NF \kappa B}$ interaction was not elucidated. For instance, the specific effect of increasing O-GlcNAcylation levels using PUGNAc or Thiamet-G was not evaluated in theses studies. Glucosamine, by increasing UDP-GlcNAc in the cell, may also affect complex glycosylations of proteins. Thus, it is possible that glucosamine effects were mediated by modification of N-linked glycosylation of receptors and/or secreted proteins, as suggested previously in a study using macrophage cell lines (74). Moreover, depending on the experimental setting, glucosamine may also induce ATP depletion (75) or promote oxidative stress (76). Therefore, glycosylationindependent effects might also play a role in the paradoxical effect of glucosamine on NFKB O-GlcNAcylation state. Further confusion was provided by an additional study by Hwang et al. (77), which showed that over-expression of OGT unexpectedly reduced the transcriptional activity of $\mathrm{NF} \kappa \mathrm{B}$ both in the absence and presence of glucosamine, resulting in inhibition of LPS-mediated expression of the NFKB target gene iNOS.

Innate immune signaling initiated by interaction of pathogen ligands with TLRs induces iNOS expression, and, subsequently, the production of $\mathrm{NO}$, which not only plays a role as a bactericidal agent but also act as an intracellular mediator. Indeed, $\mathrm{S}$-nitrosylation of cysteine thiols regulates protein activities in $\mathrm{NO}$-generating cells. Complex interactions between NO signaling and O-GlcNAcylation pathway have been suggested. Thus, in RAW264.7 cells and in mice peritoneal macrophages, Ryu et al. observed that LPS treatment induces increased global SNitrosylation of proteins, concomitant with a paradoxical denitrosylation of $S$-nitrosylated OGT (78). Denitrosylation of OGT was associated with an increase in its catalytic activity, suggesting a potential mechanism for LPS-induced O-GlcNAcylation of p65 and subsequent production of pro-inflammatory cytokines (78). On the other hand, in N9 microglia cells, Zheng et al. observed that LPS induced a (modest) reduction in global O-GlcNAcylation of proteins, associated with a reduction in OGT protein level (79). Clearly, additional work will be needed in order to untangle the complex relationships between OGT and p65 and their potential regulation by LPS, glucosamine, and S-nitrosylation signaling pathways, and to firmly establish their relative role in pro- and anti-inflammatory functions in macrophages.

\section{CONCLUSION}

Whereas the implication of hyperglycemia in metabolic syndromeassociated inflammation is now well established, the involvement of O-GlcNAcylation appears complex, with both pro- and antiinflammatory effects associated with this modification, depending on the type and duration (acute versus chronic) of the insult (80). In agreement with a dual effect of $O$-GlcNAc on inflammation, 
O-GlcNAcylation of NFKB, through an array of different mechanisms, can have both positive and negative effects on its activity depending on pathophysiological models and cell types $(31,41$, 42, 47, 48, 51, 52, 81).

Recent data suggested that O-GlcNAcylation in the immune system may participate in the pathogenesis of both type- 1 and type-2 diabetes $(48,49)$. Interestingly, O-GlcNAcylation was discovered 30 years ago in immune cells (82), and dynamic changes in $O$-GlcNAc levels upon lymphocyte activation were detected as early as the beginning of the nineties (83). However, only a limited amount of studies have investigated the function and regulation of this modification in immune cells, and very few works concern macrophages biology. This is indeed an emerging field, with many deficiencies in the existing knowledge. Several important points should be addressed in the future. Thus, the role of OGT and O-GlcNAcylation on macrophage functions (phagocytosis, ROS production in the phagosome, cytokine expression and secretion, M1 versus M2 polarization, etc.) should be thoroughly investigated. Ideally, these studies should be performed using primary cultured macrophages rather than in cell lines. In addition, the consequences of in vivo chronic hyperglycemia on protein $\mathrm{O}$ GlcNAcylation in macrophages should also be evaluated. In this context, the development of macrophages specific OGT or OGA knock-out mice should provide important clues on the role of this modification in hyperglycemia-induced inflammation. Therefore, a large continent in the $O-G l c N A c$ world remains to be explored.

\section{ACKNOWLEDGMENTS}

Léa Baudoin holds a Ph.D. fellowship from the CORDDIMIle de France. Our work is performed within the Département Hospitalo-Universitaire (DHU) AUToimmune and HORmonal diseaseS and is supported by a grant from the Société Francophone du Diabète-Antadir (2013).

\section{REFERENCES}

1. Hotamisligil GS. Inflammation and metabolic disorders. Nature (2006) 444(7121):860-7. doi:10.1038/nature05485

2. Shi H, Kokoeva MV, Inouye K, Tzameli I, Yin H, Flier JS. TLR4 links innate immunity and fatty acid-induced insulin resistance. J Clin Invest (2006) 116(11):3015-25. doi:10.1172/JCI28898

3. Esposito K, Nappo F, Marfella R, Giugliano G, Giugliano F, Ciotola M, et al. Inflammatory cytokine concentrations are acutely increased by hyperglycemia in humans: role of oxidative stress. Circulation (2002) 106(16):2067-72. doi:10. 1161/01.CIR.0000034509.14906.AE

4. Mohanty P, Hamouda W, Garg R, Aljada A, Ghanim H, Dandona P. Glucose challenge stimulates reactive oxygen species (ROS) generation by leucocytes. J Clin Endocrinol Metab (2000) 85(8):2970-3. doi:10.1210/jcem.85. 8.6854

5. Liu S, Manson JE, Buring JE, Stampfer MJ, Willett WC, Ridker PM. Relation between a diet with a high glycemic load and plasma concentrations of highsensitivity C-reactive protein in middle-aged women. Am J Clin Nutr (2002) 75(3):492-8.

6. Dickinson S, Hancock DP, Petocz P, Ceriello A, Brand-Miller J. High-glycemic index carbohydrate increases nuclear factor-kappaB activation in mononuclear cells of young, lean healthy subjects. Am J Clin Nutr (2008) 87(5):1188-93.

7. de Carvalho Vidigal F, Guedes Cocate P, Goncalves Pereira L, de Cassia Goncalves Alfenas R. The role of hyperglycemia in the induction of oxidative stress and inflammatory process. Nutr Hosp (2012) 27(5):1391-8. doi:10.3305/nh.2012. 27.5.5917

8. Dandona P, Mohanty P, Ghanim H, Aljada A, Browne R, Hamouda W, et al. The suppressive effect of dietary restriction and weight loss in the obese on the generation of reactive oxygen species by leukocytes, lipid peroxidation, and protein carbonylation. J Clin Endocrinol Metab (2001) 86(1):355-62. doi:10.1210/jcem.86.1.7150

9. Issad T, Masson E, Pagesy P. O-GlcNAc modification, insulin signaling and diabetic complications. Diabetes Metab (2010) 36(6 Pt 1):423-35. doi:10.1016/j. diabet.2010.09.001

10. Gao Y, Miyazaki J, Hart GW. The transcription factor PDX-1 is posttranslationally modified by $\mathrm{O}$-linked $\mathrm{N}$-acetylglucosamine and this modification is correlated with its DNA binding activity and insulin secretion in min6 beta-cells. Arch Biochem Biophys (2003) 415(2):155-63. doi:10.1016/S00039861(03)00234-0

11. Goldberg HJ, Whiteside CI, Hart GW, Fantus IG. Posttranslational, reversible O-glycosylation is stimulated by high glucose and mediates plasminogen activator inhibitor-1 gene expression and Sp1 transcriptional activity in glomerular mesangial cells. Endocrinology (2006) 147(1):222-31. doi:10.1210/en.2006-0523

12. Andrali SS, Qian Q, Ozcan S. Glucose mediates the translocation of NeuroD1 by O-linked glycosylation. J Biol Chem (2007) 282(21):15589-96. doi:10.1074/ jbc.M701762200

13. Kuo M, Zilberfarb V, Gangneux N, Christeff N, Issad T. O-glycosylation of FoxO1 increases its transcriptional activity towards the glucose 6-phosphatase gene. FEBS Lett (2008) 582(5):829-34. doi:10.1016/j.febslet.2008.02.010

14. Kuo M, Zilberfarb V, Gangneux N, Christeff N, Issad T. O-GlcNAc modification of FoxO1 increases its transcriptional activity: a role in the glucotoxicity phenomenon? Biochimie (2008) 90:679-85. doi:10.1016/j.biochi.2008.03.005

15. Guinez C, Filhoulaud G, Rayah-Benhamed F, Marmier S, Dubuquoy C, Dentin $\mathrm{R}$, et al. O-GlcNAcylation increases ChREBP protein content and transcriptional activity in the liver. Diabetes (2011) 60(5):1399-413. doi:10.2337/db10-0452

16. Fardini Y, Masson E, Boudah O, Ben Jouira R, Cosson C, Pierre-Eugene C, et al. O-GlcNAcylation of FoxOl in pancreatic beta cells promotes Akt inhibition through an IGFBP1-mediated autocrine mechanism. FASEB J (2014) 28(2):1010-21. doi:10.1096/fj.13-238378

17. Issad T, Kuo M. O-GlcNAc modification of transcription factors, glucose sensing and glucotoxicity. Trends Endocrinol Metab (2008) 19(10):380-9. doi:10.1016/j. tem.2008.09.001

18. Park SY, Ryu J, Lee W. O-GlcNAc modification on IRS-1 and Akt2 by PUGNAc inhibits their phosphorylation and induces insulin resistance in rat primary adipocytes. Exp Mol Med (2005) 37(3):220-9. doi:10.1038/emm.2005.30

19. Lima VV, Giachini FR, Carneiro FS, Carneiro ZN, Fortes ZB, Carvalho MH, et al. Increased vascular O-GlcNAcylation augments reactivity to constrictor stimuliVASOACTIVE PEPTIDE SYMPOSIUM. J Am Soc Hypertens (2008) 2(6):410-7. doi:10.1016/j.jash.2008.06.001

20. Luo B, Soesanto Y, McClain DA. Protein modification by O-linked GlcNAc reduces angiogenesis by inhibiting Akt activity in endothelial cells. Arterioscler Thromb Vasc Biol (2008) 28(4):651-7. doi:10.1161/ATVBAHA.107.159533

21. Yang X, Ongusaha PP, Miles PD, Havstad JC, Zhang F, So WV, et al. Phosphoinositide signalling links O-GlcNAc transferase to insulin resistance. Nature (2008) 451(7181):964-9. doi:10.1038/nature06668

22. Lefebvre T, Dehennaut V, Guinez C, Olivier S, Drougat L, Mir AM, et al. Dysregulation of the nutrient/stress sensor O-GlcNAcylation is involved in the etiology of cardiovascular disorders, type-2 diabetes and Alzheimer's disease. Biochim Biophys Acta (2009) 1800(2):67-79. doi:10.1016/j.bbagen.2009.08.008

23. Weigert C, Klopfer K, Kausch C, Brodbeck K, Stumvoll M, Haring HU, et al. Palmitate-induced activation of the hexosamine pathway in human myotubes: increased expression of glutamine:fructose-6-phosphate aminotransferase. Diabetes (2003) 52(3):650-6. doi:10.2337/diabetes.52.3.650

24. Busch AK, Cordery D, Denyer GS, Biden TJ. Expression profiling of palmitateand oleate-regulated genes provides novel insights into the effects of chronic lipid exposure on pancreatic beta-cell function. Diabetes (2002) 51(4):977-87. doi:10.2337/diabetes.51.4.977

25. Schrijvers BF, De Vriese AS. Novel insights in the treatment of diabetic nephropathy. Acta Clin Belg (2007) 62(5):278-90. doi:10.1179/acb.2007.043

26. Haneda M, Koya D, Isono M, Kikkawa R. Overview of glucose signaling in mesangial cells in diabetic nephropathy. J Am Soc Nephrol (2003) 14(5):1374-82. doi:10.1097/01.ASN.0000064500.89551.76

27. Stockand JD, Sansom SC. Glomerular mesangial cells: electrophysiology and regulation of contraction. Physiol Rev (1998) 78(3):723-44.

28. Kolm-Litty V, Sauer U, Nerlich A, Lehmann R, Schleicher ED. High glucoseinduced transforming growth factor betal production is mediated by the hexosamine pathway in porcine glomerular mesangial cells. J Clin Invest (1998) 101(1):160-9. doi:10.1172/JCI119875 
29. Weigert C, Friess U, Brodbeck K, Haring HU, Schleicher ED. Glutamine:fructose6-phosphate aminotransferase enzyme activity is necessary for the induction of TGF-betal and fibronectin expression in mesangial cells. Diabetologia (2003) 46(6):852-5. doi:10.1007/s00125-003-1122-8

30. Goldberg HJ, Whiteside CI, Fantus IG. The hexosamine pathway regulates the plasminogen activator inhibitor-1 gene promoter and Sp1 transcriptional activation through protein kinase C-beta I and -delta. J Biol Chem (2002) 277(37):33833-41. doi:10.1074/jbc.M112331200

31. James LR, Tang D, Ingram A, Ly H, Thai K, Cai L, et al. Flux through the hexosamine pathway is a determinant of nuclear factor kappaB-dependent promoter activation. Diabetes (2002) 51(4):1146-56. doi:10.2337/diabetes.51. 4.1146

32. Yerneni KK, Bai W, Khan BV, Medford RM, Natarajan R. Hyperglycemia-induced activation of nuclear transcription factor kappaB in vascular smooth muscle cells. Diabetes (1999) 48(4):855-64. doi:10.2337/diabetes.48.4.855

33. Hofmann MA, Schiekofer S, Kanitz M, Klevesath MS, Joswig M, Lee V, et al. Insufficient glycemic control increases nuclear factor-kappa B binding activity in peripheral blood mononuclear cells isolated from patients with type 1 diabetes. Diabetes Care (1998) 21(8):1310-6. doi:10.2337/diacare. 21.8.1310

34. Hofmann MA, Schiekofer S, Isermann B, Kanitz M, Henkels M, Joswig M, et al. Peripheral blood mononuclear cells isolated from patients with diabetic nephropathy show increased activation of the oxidative-stress sensitive transcription factor NF-kappaB. Diabetologia (1999) 42(2):222-32. doi:10.1007/ s001250051142

35. Brownlee M. Biochemistry and molecular cell biology of diabetic complications. Nature (2001) 414(6865):813-20. doi:10.1038/414813a

36. Du XL, Edelstein D, Rossetti L, Fantus IG, Goldberg H, Ziyadeh F, et al. Hyperglycemia-induced mitochondrial superoxide overproduction activates the hexosamine pathway and induces plasminogen activator inhibitor-1 expression by increasing Spl glycosylation. Proc Natl Acad Sci U S A (2000) 97(22):12222-6. doi:10.1073/pnas.97.22.12222

37. Brownlee M. The pathobiology of diabetic complications: a unifying mechanism. Diabetes (2005) 54(6):1615-25. doi:10.2337/diabetes.54.6.1615

38. Sen R, Baltimore D. Inducibility of kappa immunoglobulin enhancer-binding protein Nf-kappa B by a posttranslational mechanism. Cell (1986) 47(6):921-8. doi:10.1016/0092-8674(86)90807-X

39. Sen R, Baltimore D. Multiple nuclear factors interact with the immunoglobulin enhancer sequences. Cell (1986) 46(5):705-16. doi:10.1016/0092-8674(86) 90346-6

40. Oeckinghaus A, Ghosh S. The NF-kappaB family of transcription factors and its regulation. Cold Spring Harb Perspect Biol (2009) 1(4):a000034. doi:10.1101/ cshperspect.a000034

41. Yang WH, Park SY, Nam HW, Kim do H, Kang JG, Kang ES, et al. NFkap$\mathrm{paB}$ activation is associated with its O-GlcNAcylation state under hyperglycemic conditions. Proc Natl Acad Sci U S A (2008) 105(45):17345-50. doi:10.1073/pnas.0806198105

42. Allison DF, Wamsley JJ, Kumar M, Li D, Gray LG, Hart GW, et al. Modification of RelA by O-linked N-acetylglucosamine links glucose metabolism to NF-kappaB acetylation and transcription. Proc Natl Acad Sci US A (2012) 109(42):16888-93. doi:10.1073/pnas.1208468109

43. Yuan M, Konstantopoulos N, Lee J, Hansen L, Li ZW, Karin M, et al. Reversal of obesity- and diet-induced insulin resistance with salicylates or targeted disruption of Ikkbeta. Science (2001) 293(5535):1673-7. doi:10.1126/science. 1061620

44. Cai D, Yuan M, Frantz DF, Melendez PA, Hansen L, Lee J, et al. Local and systemic insulin resistance resulting from hepatic activation of IKK-beta and NF-kappaB. Nat Med (2005) 11(2):183-90. doi:10.1038/nm1166

45. Itani SI, Ruderman NB, Schmieder F, Boden G. Lipid-induced insulin resistance in human muscle is associated with changes in diacylglycerol, protein kinase C, and IkappaB-alpha. Diabetes (2002) 51(7):2005-11. doi:10.2337/ diabetes.51.7.2005

46. Dandona P, Aljada A, Chaudhuri A, Mohanty P, Garg R. Metabolic syndrome: a comprehensive perspective based on interactions between obesity, diabetes, and inflammation. Circulation (2005) 111(11):1448-54. doi:10.1161/01.CIR. 0000158483.13093.9D

47. Golks A, Tran TT, Goetschy JF, Guerini D. Requirement for O-linked Nacetylglucosaminyltransferase in lymphocytes activation. EMBO J (2007) 26(20):4368-79. doi:10.1038/sj.emboj.7601845
48. Ramakrishnan P, Clark PM, Mason DE, Peters EC, Hsieh-Wilson LC, Baltimore D. Activation of the transcriptional function of the NF-kappaB protein c-Rel by O-GlcNAc glycosylation. Sci Signal (2013) 6(290):ra75. doi:10.1126/scisignal. 2004097

49. Hart GW. Nutrient regulation of immunity: O-GlcNAcylation regulates stimulus-specific NF-kappaB-dependent transcription. Sci Signal (2013) 6(290):e26. doi:10.1126/scisignal.2004596

50. Kawauchi K, Araki K, Tobiume K, Tanaka N. Loss of p53 enhances catalytic activity of IKKbeta through O-linked beta-N-acetyl glucosamine modification. Proc Natl Acad Sci U S A (2009) 106(9):3431-6. doi:10.1073/pnas. 0813210106

51. Zou L, Yang S, Hu S, Chaudry IH, Marchase RB, Chatham JC. The protective effects of PUGNAc on cardiac function after trauma-hemorrhage are mediated via increased protein O-GlcNAc levels. Shock (2007) 27(4):402-8 doi:10.1097/01.shk.0000245031.31859.29

52. Zou L, Yang S, Champattanachai V, Hu S, Chaudry IH, Marchase RB, et al. Glucosamine improves cardiac function following trauma-hemorrhage by increased protein O-GlcNAcylation and attenuation of NF-\{kappa $\}$ B signaling. Am J Physiol Heart Circ Physiol (2009) 296(2):H515-23. doi:10.1152/ajpheart. 01025.2008

53. Xing D, Gong K, Feng W, Nozell SE, Chen YF, Chatham JC, et al. O-GlcNAc modification of NFkappaB p65 inhibits TNF-alpha-induced inflammatory mediator expression in rat aortic smooth muscle cells. PLoS One (2011) 6(8):e24021. doi:10.1371/journal.pone.0024021

54. Xing D, Feng W, Not LG, Miller AP, Zhang Y, Chen YF, et al. Increased protein O-GlcNAc modification inhibits inflammatory and neointimal responses to acute endoluminal arterial injury. Am J Physiol Heart Circ Physiol (2008) 295(1):H335-42. doi:10.1152/ajpheart.01259.2007

55. Hilgers RH, Xing D, Gong K, Chen YF, Chatham JC, Oparil S. Acute OGlcNAcylation prevents inflammation-induced vascular dysfunction. Am J Physiol Heart Circ Physiol (2012) 303(5):H513-22. doi:10.1152/ajpheart.01175. 2011

56. Xu H, Barnes GT, Yang Q, Tan G, Yang D, Chou CJ, et al. Chronic inflammation in fat plays a crucial role in the development of obesity-related insulin resistance. J Clin Invest (2003) 112(12):1821-30. doi:10.1172/JCI19451

57. Weisberg SP, McCann D, Desai M, Rosenbaum M, Leibel RL, Ferrante AW Jr. Obesity is associated with macrophage accumulation in adipose tissue. J Clin Invest (2003) 112(12):1796-808. doi:10.1172/JCI19246

58. Obstfeld AE, Sugaru E, Thearle M, Francisco AM, Gayet C, Ginsberg HN, et al. C-C chemokine receptor 2 (CCR2) regulates the hepatic recruitment of myeloid cells that promote obesity-induced hepatic steatosis. Diabetes (2010) 59(4):916-25. doi:10.2337/db09-1403

59. Ehses JA, Perren A, Eppler E, Ribaux P, Pospisilik JA, Maor-Cahn R, et al. Increased number of islet-associated macrophages in type 2 diabetes. Diabetes (2007) 56(9):2356-70. doi:10.2337/db06-1650

60. Eriksson EE, Xie X, Werr J, Thoren P, Lindbom L. Importance of primary capture and L-selectin-dependent secondary capture in leukocyte accumulation in inflammation and atherosclerosis in vivo. J Exp Med (2001) 194(2):205-18. doi:10.1084/jem.194.2.205

61. Osborn O, Olefsky JM. The cellular and signaling networks linking the immune system and metabolism in disease. Nat Med (2012) 18(3):363-74. doi: $10.1038 / \mathrm{nm} .2627$

62. Stohr R, Federici M. Insulin resistance and atherosclerosis: convergence between metabolic pathways and inflammatory nodes. Biochem J (2013) 454(1):1-11. doi:10.1042/BJ20130121

63. Shanmugam N, Reddy MA, Guha M, Natarajan R. High glucose-induced expression of proinflammatory cytokine and chemokine genes in monocytic cells. Diabetes (2003) 52(5):1256-64. doi:10.2337/diabetes.52.5.1256

64. Dasu MR, Devaraj S, Zhao L, Hwang DH, Jialal I. High glucose induces toll-like receptor expression in human monocytes: mechanism of activation. Diabetes (2008) 57(11):3090-8. doi:10.2337/db08-0564

65. Hua KF, Wang SH, Dong WC, Lin CY, Ho CL, Wu TH. High glucose increases nitric oxide generation in lipopolysaccharide-activated macrophages by enhancing activity of protein kinase C-alpha/delta and NF-kappaB. Inflamm Res (2012) 61(10):1107-16. doi:10.1007/s00011-012-0503-1

66. Donath MY. Targeting inflammation in the treatment of type 2 diabetes: time to start. Nat Rev Drug Discov (2014) 13(6):465-76. doi:10.1038/nrd4275

67. Ptak W, Klimek M, Bryniarski K, Ptak M, Majcher P. Macrophage function in alloxan diabetic mice: expression of adhesion molecules, generation of 
monokines and oxygen and NO radicals. Clin Exp Immunol (1998) 114(1):13-8. doi:10.1046/j.1365-2249.1998.00687.x

68. Wen Y, Gu J, Li SL, Reddy MA, Natarajan R, Nadler JL. Elevated glucose and diabetes promote interleukin-12 cytokine gene expression in mouse macrophages. Endocrinology (2006) 147(5):2518-25. doi:10.1210/en.2005-0519

69. Sun C, Sun L, Ma H, Peng J, Zhen Y, Duan K, et al. The phenotype and functional alterations of macrophages in mice with hyperglycemia for long term. $J$ Cell Physiol (2012) 227(4):1670-9. doi:10.1002/jcp.22891

70. Yamasawa H, Nakayama M, Bando M, Sugiyama Y. Impaired inflammatory responses to multiple toll-like receptor ligands in alveolar macrophages of streptozotocin-induced diabetic mice. Inflamm Res (2012) 61(5):417-26. doi:10.1007/s00011-011-0426-2

71. Chikanishi T, Fujiki R, Hashiba W, Sekine H, Yokoyama A, Kato S. Glucoseinduced expression of MIP-1 genes requires O-GlcNAc transferase in monocytes. Biochem Biophys Res Commun (2010) 394(4):865-70. doi:10.1016/j.bbrc. 2010.02.167

72. Hwang SY, Shin JH, Hwang JS, Kim SY, Shin JA, Oh ES, et al. Glucosamine exerts a neuroprotective effect via suppression of inflammation in rat brain ischemia/reperfusion injury. Glia (2010) 58(15):1881-92. doi:10.1002/glia. 21058

73. Hwang SY, Hwang JS, Kim SY, Han IO. O-GlcNAcylation and p50/p105 binding of c-Rel are dynamically regulated by LPS and glucosamine in BV2 microglia cells. Br J Pharmacol (2013) 169(7):1551-60. doi:10.1111/bph.12223

74. Anagnostou SH, Shepherd PR. Glucose induces an autocrine activation of the Wnt/beta-catenin pathway in macrophage cell lines. Biochem J (2008) 416(2):211-8. doi:10.1042/BJ20081426

75. Hresko RC, Heimberg H, Chi MM, Mueckler M. Glucosamine-induced insulin resistance in 3T3-L1 adipocytes is caused by depletion of intracellular ATP. J Biol Chem (1998) 273(32):20658-68. doi:10.1074/jbc.273.32.20658

76. Kaneto H, Xu G, Song KH, Suzuma K, Bonner-Weir S, Sharma A, et al. Activation of the hexosamine pathway leads to deterioration of pancreatic betacell function through the induction of oxidative stress. J Biol Chem (2001) 276(33):31099-104. doi:10.1074/jbc.M104115200

77. Hwang SY, Hwang JS, Kim SY, Han IO. O-GlcNAc transferase inhibits LPSmediated expression of inducible nitric oxide synthase through an increased interaction with mSin3A in RAW264.7 cells. Am J Physiol Cell Physiol (2013) 305(6):C601-8. doi:10.1152/ajpcell.00042.2013
78. Ryu IH, Do SI. Denitrosylation of S-nitrosylated OGT is triggered in LPSstimulated innate immune response. Biochem Biophys Res Commun (2011) 408(1):52-7. doi:10.1016/j.bbrc.2011.03.115

79. Zheng GM, Yu C, Yang Z. Puerarin suppresses production of nitric oxide and inducible nitric oxide synthase in lipopolysaccharide-induced N9 microglial cells through regulating MAPK phosphorylation, O-GlcNAcylation and NF-kappaB translocation. Int J Oncol (2012) 40(5):1610-8. doi:10.3892/ijo. 2012.1331

80. Lima VV, Spitler K, Choi H, Webb RC, Tostes RC. O-GlcNAcylation and oxidation of proteins: is signalling in the cardiovascular system becoming sweeter? Clin Sci (Lond) (2012) 123(8):473-86. doi:10.1042/CS20110638

81. Ma Z, Vocadlo DJ, Vosseller K. Hyper-O-GlcNAcylation is anti-apoptotic and maintains constitutive NF-kappaB activity in pancreatic cancer cells. J Biol Chem (2013) 288(21):15121-30. doi:10.1074/jbc.M113.470047

82. Torres CR, Hart GW. Topography and polypeptide distribution of terminal Nacetylglucosamine residues on the surfaces of intact lymphocytes. Evidence for O-linked GlcNAc. J Biol Chem (1984) 259(5):3308-17.

83. Kearse KP, Hart GW. Lymphocyte activation induces rapid changes in nuclear and cytoplasmic glycoproteins. Proc Natl Acad Sci U S A (1991) 88(5):1701-5. doi:10.1073/pnas.88.5.1701

Conflict of Interest Statement: The authors declare that the research was conducted in the absence of any commercial or financial relationships that could be construed as a potential conflict of interest.

Received: 05 October 2014; accepted: 18 December 2014; published online: 09 January 2015.

Citation: Baudoin L and Issad T (2015) O-GlcNAcylation and inflammation: a vast territory to explore. Front. Endocrinol. 5:235. doi: 10.3389/fendo.2014.00235

This article was submitted to Molecular and Structural Endocrinology, a section of the journal Frontiers in Endocrinology.

Copyright $\odot 2015$ Baudoin and Issad. This is an open-access article distributed under the terms of the Creative Commons Attribution License (CC BY). The use, distribution or reproduction in other forums is permitted, provided the original author(s) or licensor are credited and that the original publication in this journal is cited, in accordance with accepted academic practice. No use, distribution or reproduction is permitted which does not comply with these terms. 